\title{
The impact of skeletal muscle injury on the expression of laminin and its role in regeneration
}

\author{
Taghreed A. Ali ${ }^{1}$, Laith H. Zaki ${ }^{2}$ and May F. Al-Habib ${ }^{3}$ \\ ${ }^{1}$ Al- Turath University College, Baghdad, Iraq \\ ${ }^{2}$ Directory of Military Medical Affairs, Iraqi Ministry of Defence, Baghdad, Iraq \\ ${ }^{3}$ Department of Anatomy, Histology and Embryology, College of Medicine, Al-Nahrain University, Baghdad, Iraq
}

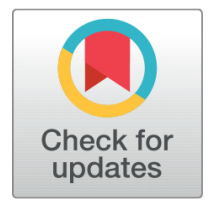

Received 31-08-2020
Revised 15-09-2020
Accepted 18-12-2020
Published 31-12-2020

Corresponding Author

May F. Al-Habib

mayalhabib@yahoo.com

Department of Anatomy, Histology and Embryology, College of Medicine, Al-Nahrain University, Baghdad, Iraq

DOI https://doi.org/10.47419/ bjbabs.v1i01.29

Pages: 27-40

Distributed under the terms of the Creative Commons

Attribution-NonCommercial 4.0 International (CC-BY-NC 4.0), which permits use for any non-commercial purpose, distribution, and reproduction in any medium, provided that the original work is properly cited.

Copyright: (c) 2020 Taghreed A. Ali, Laith H. Zaki, May F. Al-Habib

\section{ABSTRACT}

Background: Laminins are high-molecular-weight proteins in the extracellular matrix; it is a major component of the basal lamina, influencing cell differentiation, migration, and adhesion. Laminin affects cell growth, besides effects in wound healing and embryonic development.

Objectives: The present study aims to assess the histological changes taking place during skeletal muscle healing.

Methods: The Extensor digitorum longus muscle of 45 male rabbits was set as a skeletal muscle injury model and examined $3 \& 6$ weeks after initiation of injury. These animals were divided into three groups control (A) group with no injury, group (B) at $3^{\text {rd }}$ post-injury week, group (C) at $6^{\text {th }}$ post-injury week. The muscle tissues were prepared and examined histologically using H\&E and immunohistochemically using Laminin antibodies. Aperio image scope software is used to analyze immunohistochemical reactivity quantitatively. The degeneration and regeneration process were overlapping with each other both in time and cellular morphological changes. Early myoblast like cell appearance and new myotube formation was recorded during the $3^{\text {rd }}$ week. By the end of the $6^{\text {th }}$-week postoperatively, the muscle histological maturation and muscle fascicles were noticed.

Results: Immunohistochemical reactivity of Laminin antibody showed an intense reactivity in the $3^{\text {rd }}$-week group while a less intense reactivity in the control and $6^{\text {th }}$-week groups.A quantitative assessment of Laminin using Aperio soft wear showed that the $3^{r d}$-week group has an intensity of $0.724 \pm 0.03$ pixel, while the $6^{\text {th }}$ week's group was $0.321 \pm 0.02$ pixel and the control groups was $0.293 \pm 0.02$ pixel. The differences were statistically significant, P-value $\leq 0.0001$.

Conclusion: The process of regeneration is a dynamic type where degeneration and regeneration superimposed each other.

Keywords immunohistochemistry, laminin, muscle injury, muscle regeneration

\section{OPEN ACCESS}




\section{INTRODUCTION}

Skeletal muscle has an excellent ability to regenerate; muscle regeneration recapitulates many aspects of embryonic myogenesis and is an important homeostatic process of the adult skeletal muscle. After development, it retains the capacity to regenerate in response to appropriate stimuli. Loss of control over muscle precursor cell could lead to pathological trans-differentiation leading to pathologic defect in the regenerative process. ${ }^{1}$

Muscle tissue repair following damage can be considered as a process consisting of two interdependent phases: degeneration and regeneration, where, apart from the role of growth and differentiation factors, the degree of damage and the interactions between muscle and the infiltrating inflammatory cells appear to affect the successful outcome of the muscle repair process, muscle regeneration depends on a balance between proinflammatory and anti-inflammatory factors that determine whether the damage will be resolved with muscle fiber replacement and reconstitution of a functional contractile apparatus, or with scar formation. ${ }^{2}$

Skeletal muscle repair is a highly synchronized process involving the activation of various cellular and molecular responses, where the coordination between inflammation and regeneration is crucial for the beneficial outcome of the repair process following muscle damage. $^{3}$

Regulation of Laminin deposition in the matrix is by cell-surface receptors following their secretion as intact heterotrimers; Laminins are deposited into the extracellular matrix, some Laminin molecules are subsequently proteolytically processed, this processing event might modulate binding of the Laminin to cell-surface receptors regardless of the processing; however, emerging data indicate cell-surface receptors, integrins and dystroglycan regulate that deposition and/or formation of Laminin matrices, and that other matrix components stabilize Laminin incorporation into the extracellular matrix. ${ }^{4,5}$

The present study aimed to focus on the role of Laminin during the process of regeneration and to evaluate the expression of Laminin in skeletal muscle regeneration both quantitatively and histologically.

\section{MATERIALS AND METHODS Induction of muscle injury}

The present study was performed on 40 mature male rabbits after the Institutional Review Board (IRB) approval in Al-Nahrain Medical College. The experiment complied with the national institute of health guidelines for the care and use of laboratory animals. The injury was done under general anesthesia; each animal was anesthetized with a mix of ketamine $(35 \mathrm{mg} / \mathrm{kg})$ and xylazine $(5 \mathrm{mg} / \mathrm{kg})$, according to National Institute of Health (NIH). The skin was incised after sterilization, the subcutaneous fascia and deep fascia were dissected. The extensor digitorum longus muscle was cut and then immediately returned to its position. The dissected muscle was sutured, and the half splint was applied for a week to 
limit the movement; then, the extensor digitorum longus muscle was taken after $3 \& 6$ weeks of operation.

\section{Sampling and histological tissue preparation}

Three groups of animals was set in this study each with 15 animals: Group A: (Control group) not subjected to surgical injury. Group B and Group C (experimental groups) each 15 animal in $3^{r d}$ and $6^{\text {th }}$ postoperatively week. Tissue samples were fixed in buffered formaldehyde $10 \%$, dehydrated in different concentrations of alcohol, clearing in xylene, embedded in paraffin, serially sectioned at $4 \mathrm{um}-6 \mathrm{um}$, and stained with H\&E.

\section{Laminin antibodies immunohistochemistry (IHC)}

Paraffin tissue sections placed on positively changed slide sections were deparaffinized and processed with Laminin Ab procedure.

\section{Morphometric analysis and statistical analysis}

Different fields of the section selected for imaging using a microscope digital optic camera. Immunohistochemical study was performed using Aperio positive pixel count algorithms program V10 used to quantify the amount of positive reactivity in a tissue section; this system had a set of default input parameters configured for brown color quantification in three intensity degrees, weak positive, positive, and strong positive. Statistical analysis in the present study was performed using SAS $2012 .{ }^{6}$

\section{RESULTS}

\section{Gross morphological events of skeletal muscle}

EDL muscle was chosen as an experimental model because it's easily approachable in dissection. Skeletal muscle regeneration was followed postoperatively at 2 different times, $3^{r d}$-week postoperative period because it represents the peak of regeneration and $6^{\text {th }}$ week because it represents the final picture for regenerative.

Gross examination of the muscle at $6^{\text {th }}$-week post-injury revealed the presence of an intact muscle at the site of healed injury, while the $3^{r d}$-week cross-examination showed that the site of injury was still weak, uneven, and narrow; some of the injured muscle ended in fibrous tissue formation and scar represents a failure of regeneration few cases of infection 
at the site of injury happened.

\section{Histoarchitectural regenerative dynamics in skeletal muscle regeneration}

Early stages of regeneration showed the start of the degenerative process at the site of injury, where infiltration of the inflammatory cell was observed at the site of injury and even in between intact peripheral muscle fiber (Figure 1). Muscle cells at the site of injury start to degenerate through the early stages after injury (seen in the preliminary study), and by the start of the $3^{\text {rd }}$ week, regenerative process noted young muscle fibers that start to appear within the auto grafted muscle, still, there was an infiltration of mononuclear inflammatory cells at this site injury with a large amount of connective tissue in between these new muscle fibers (Figure 2).

By the $3^{\text {rd }}$ postoperative week, synchronized balanced activity between degeneration and regeneration happened. A degenerative process which was represented by infiltration of different type of inflammatory cells occupy spaces between degeneration muscle cells and ultimately entered perimysium, and endomysium was accompanied by the appearance of new muscle fiber and high vascular infiltration of small blood vessels, the process of degeneration and regeneration in skeletal muscle overlapped each other both in time and morphological changes. By the time when revascularization started, inflammatory cells started to abolish, and at the same time, new muscle cell fibers started to appear; the whole process was very dynamic (Figure 1\&2).

Early myoblast-like cells appear at the $3^{\text {rd }}$ postoperative week seen as groups of small, rounded cells with a small nucleus centrally located and eosinophilic cytoplasm. Myoblast starts to arrange themselves in a row or longitudinal manner to form what is called the train or early myotube (Figure 2)

As the process continues, the spaces occupied by connective tissue element start to diminish and well- identified epimysium, but perimysium started to be formed, which was highly vasculature and by the end of $6^{\text {th }}$ week, fully matured muscle fibers were seen although the number of nuclei per cell was more than normal, and connective tissue element was still arranged in a non-uniform manner, (Figure 3).

\section{General distribution of laminin antibodies in regenerating muscle fibers}

Laminin expression was found to be restricted to the basement membrane (endomysium) and was seen as thin brown to dark yellow line surrounding individual muscle and separating muscle from each other (Figure 4). The sarcoplasm of these muscles was devoided from any Laminin reactively, blood vessels found in the connective tissue between muscle fibers showed well-identified reactivity (Figure $4 \& 5$ ). The third-week postoperative 


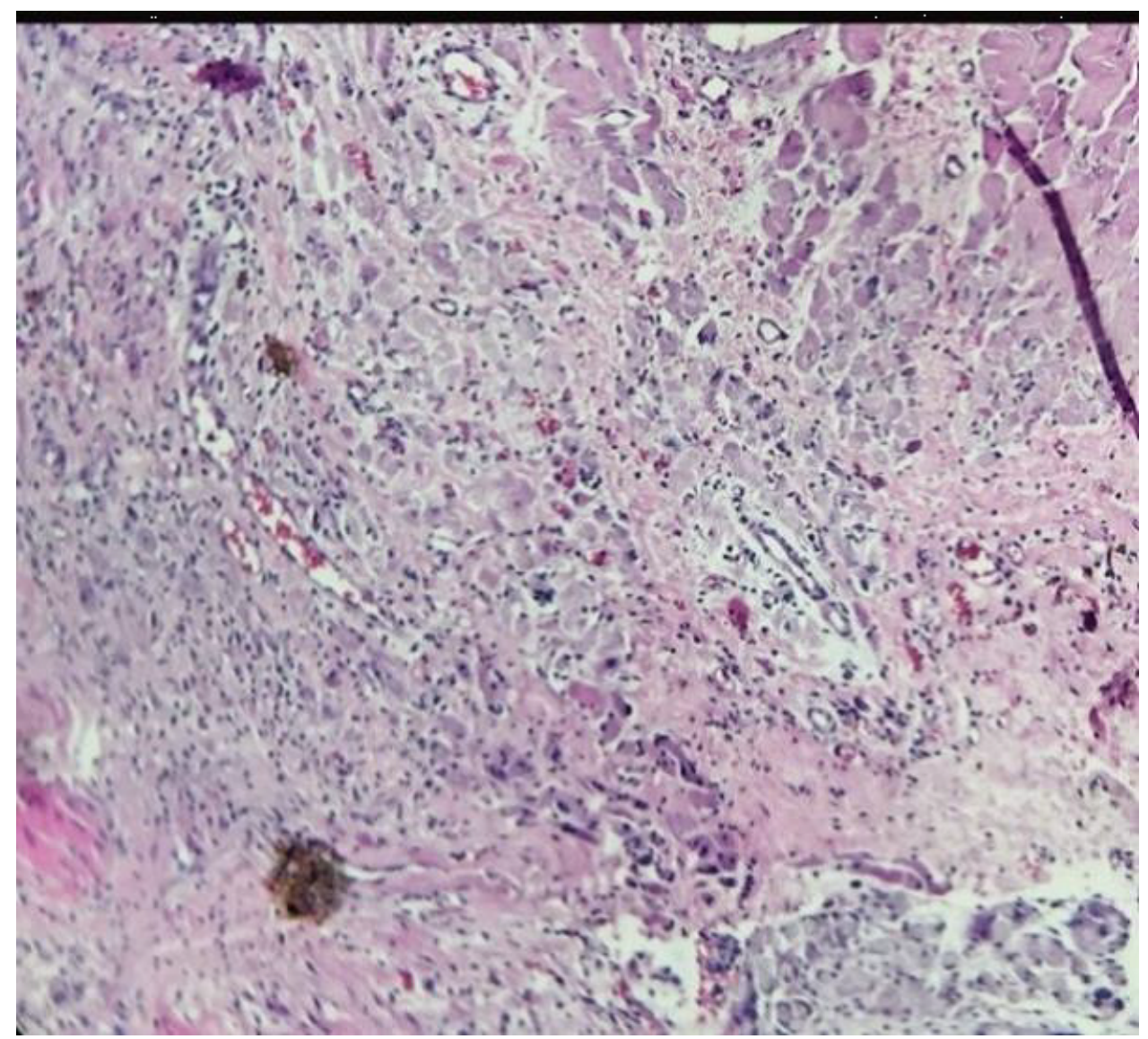

Figure 1 Cross section in regenerating skeletal muscle showing heavy mononuclear cells infiltra$\operatorname{tion}(\mathrm{MN})$ at the site of the injury with few intact peripheral muscle cell fibers, H\&E, $1^{\text {st }}$ week, X20 cross section in regenerating muscle showing newly formed small muscle fibers, high vascularity and disorganized connective tissue elements $\left(\mathrm{H} \& \mathrm{E}, 3^{\text {rd }}\right.$ week, X20).

group showed a different picture of that seen in control, foci of new muscle formation at the site of injury was seen, where small tiny muscle appeared aggregated in a disorganized way (Figure6). The new muscle fibers showed marked well-identified sarcoplasmic reactivity, and in addition to that, these multiple foci at the site of injury showed different levels of expression toward Laminin Abs (Figure 7).

By the end of the $6^{\text {th }}$ week postoperatively showed mature muscle, well organized with faint reactivity toward Laminin $\mathrm{Ab}$, which was mainly confined to the endomysium and perimysium surround blood vessels; theses mature cells showed negative reactivity in their sarcoplasm. Still in between these, mature regenerated fibers. Small regenerating foci were present, and at higher magnification, high positive reactivity toward Laminin Abs was seen represented by yellow to brown color (Figure $8 \& 9$ ).In the $6^{\text {th }}$ week, postoperative group Laminin reaction was confined to the area surrounding each muscle fiber, with mild reaction at connective tissue separating muscle fibers where blood vessels are present. The reaction in endomysium and perimysium was the same (Figure 9). 


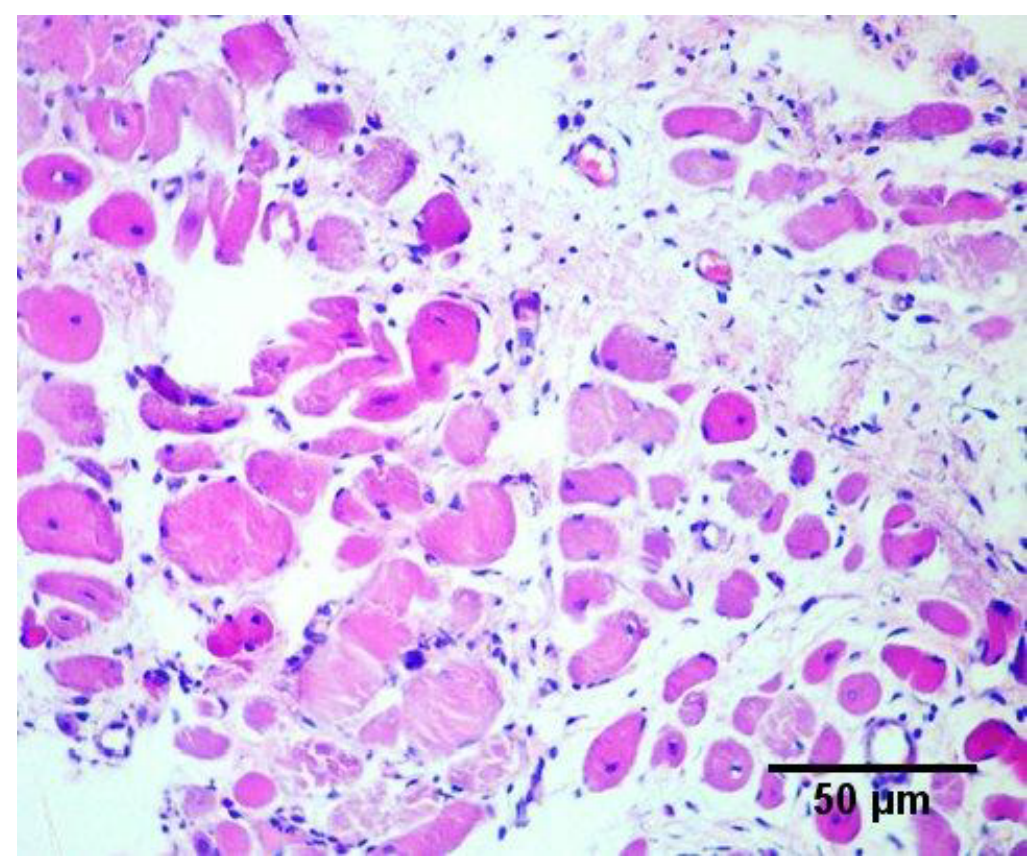

Figure 2 Cross section in regenerating muscle showing newly formed small muscle fibers, highvascularity and disorganized connective tissue elements (H\&E, $3^{\text {rd }}$ week, X20).

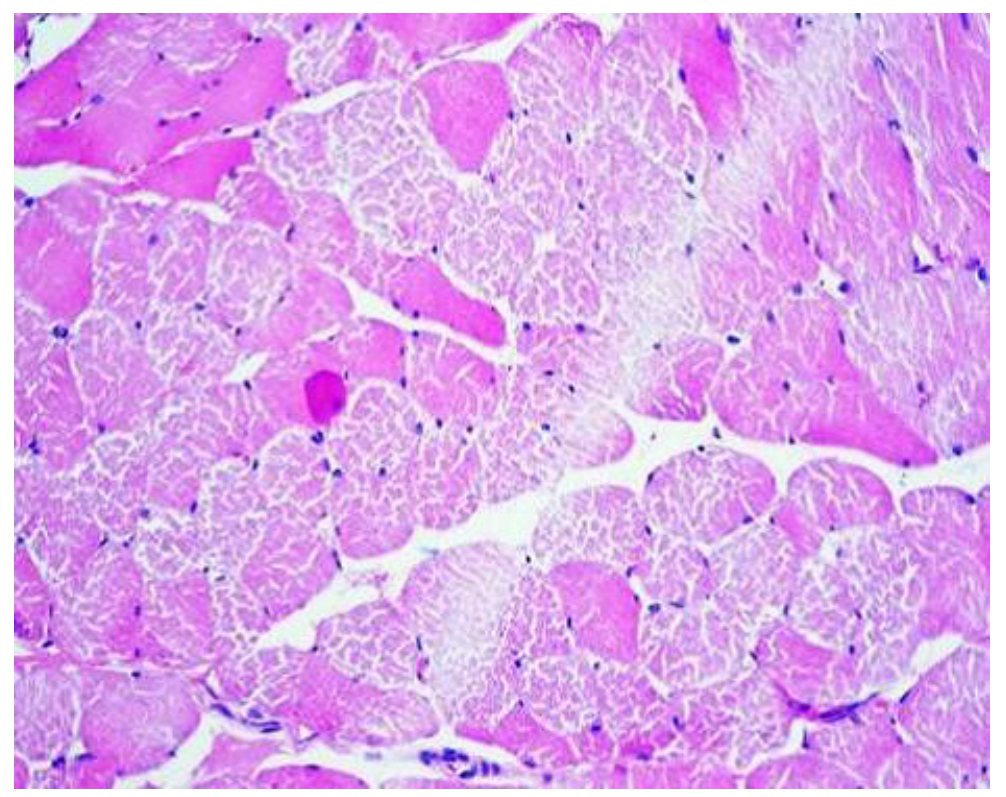

Figure 3 Cross section in regenerating skeletal muscle showing mature well organized regenerated muscle fibers. Notice the presence of mature cells with non-well organized myofilaments versus immature disorganized myofilements cells $\left(\mathrm{H} \& \mathrm{E}, 6^{\text {th }}\right.$ week, $\left.\mathrm{X} 40\right)$. 

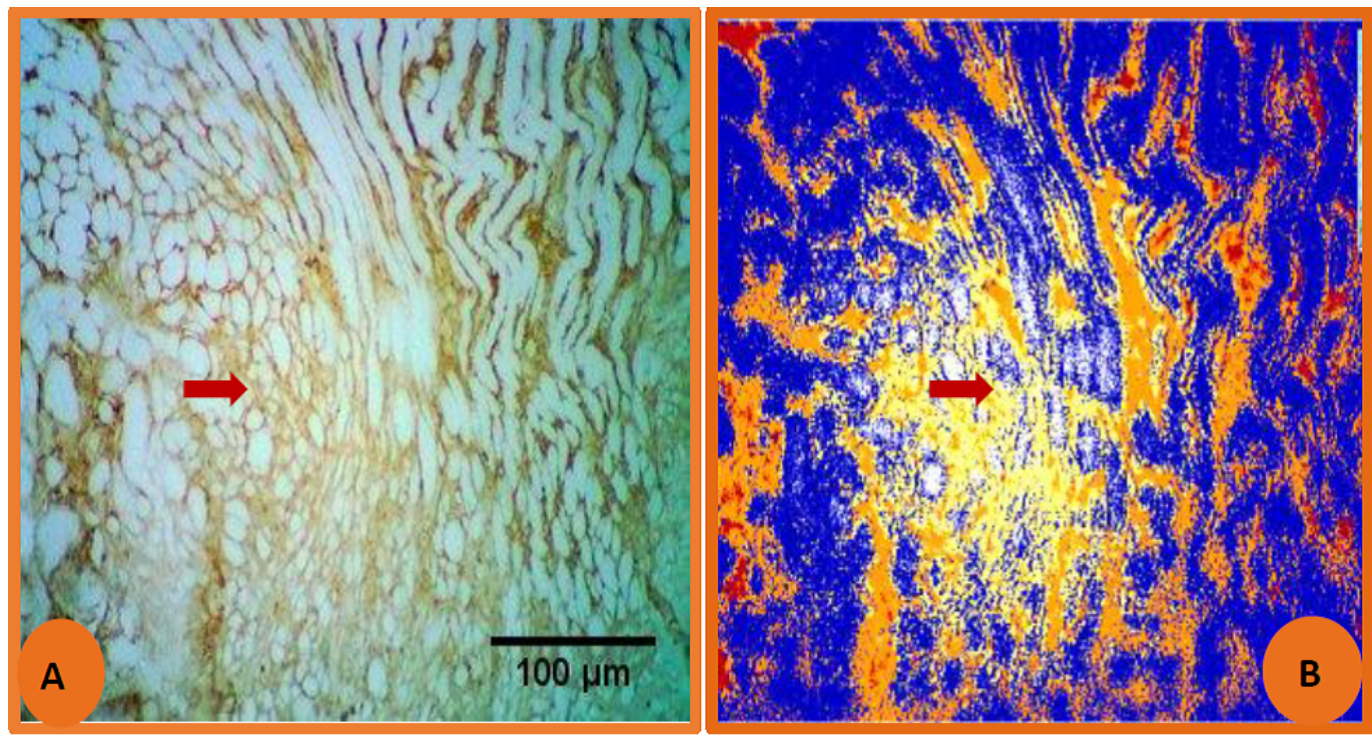

Figure 4 Cross section in normal skeletal muscle showing A: weak reactivity of laminin in sarcoplasm ( Red Arrow ).Intense reaction located at endomysium \& perimysium of muscle fiber indicated by the brown to yellow color in the connective tissue.

B: The same picture with aperio software, (control group, laminin Ab, X10).
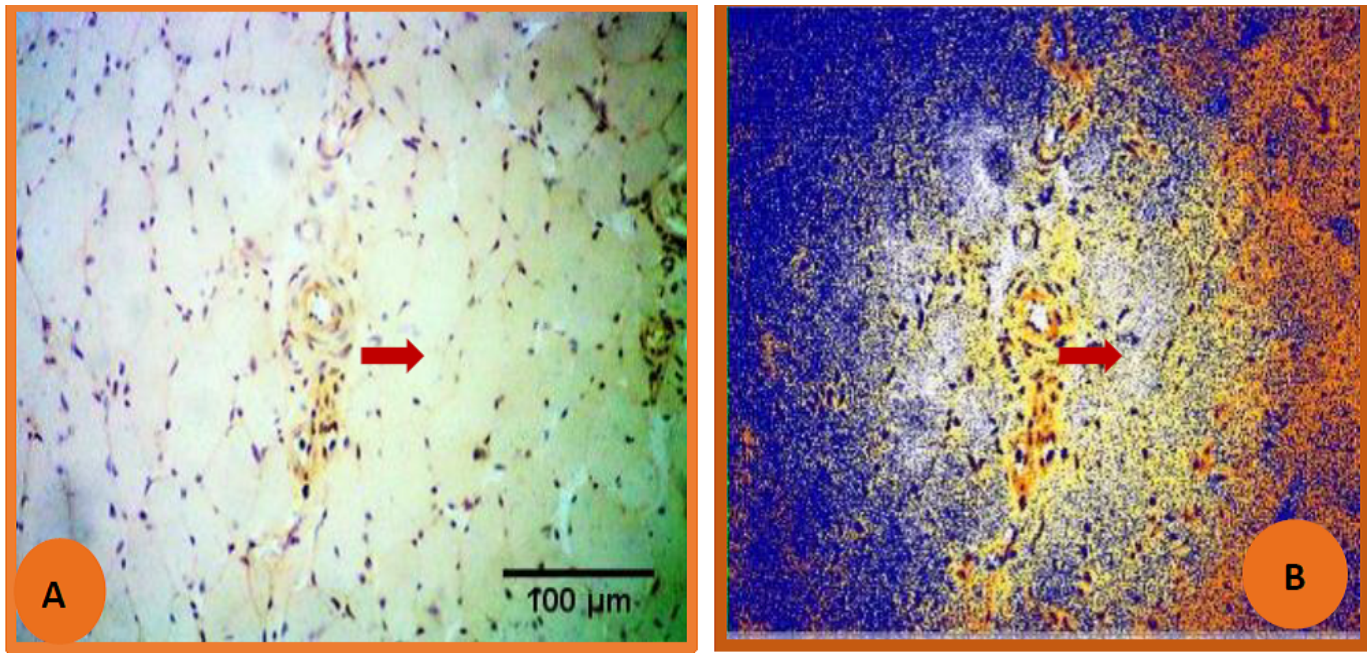

Figure 5 Cross section innormal skeletal muscle showing A: distributionof laminin Ab localizes in cell surrounding \& connective tissue elementwith blood vessels (red arrow)

B: The same picture seen with aperiosoftware (Control group, laminin Ab, week, X20) 

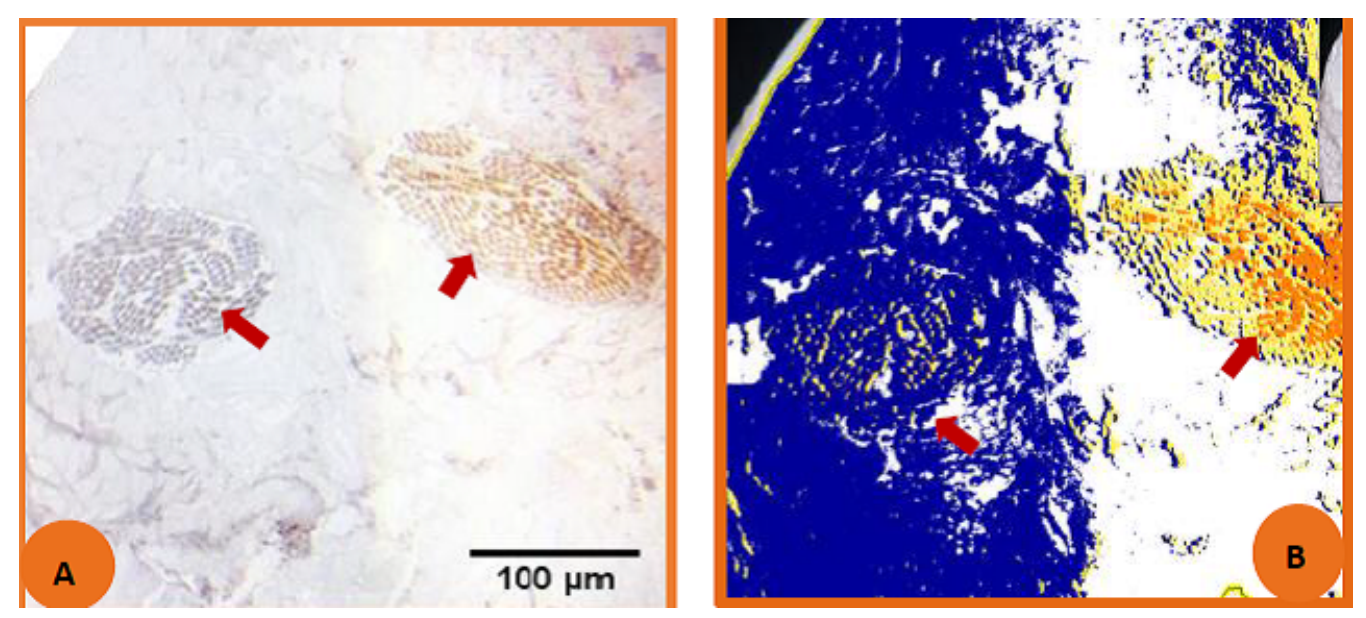

Figure 6 Cross section in regenerating skeletal muscle showing A: regenerating foci at the site of injury with different level of laminin reactivity

B: the same picture with aperio software notice laminin position reactivity difference in both foci $\left(3^{\text {rd }}\right.$ week group, laminin $\mathrm{AB}, \mathrm{X10})$.

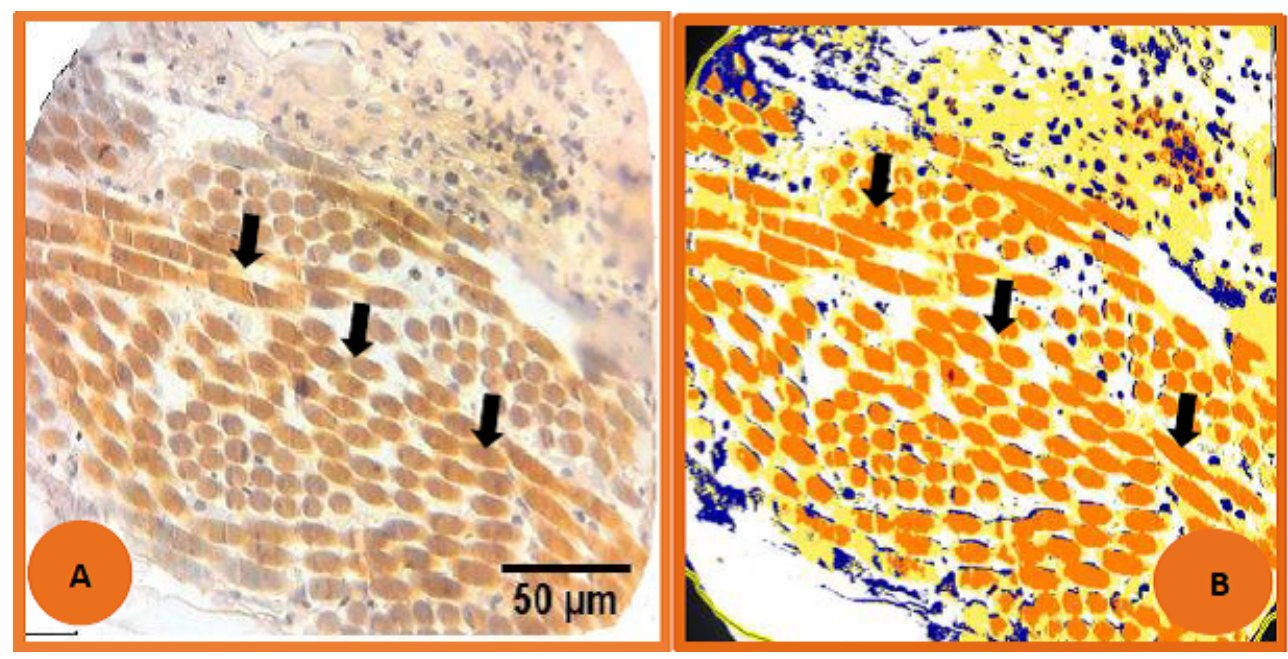

Figure 7 Cross section in regenerating muscle showing A: newly formed cell in regenerating foci with clear sarcoplasmic reactivity

$\mathrm{B}$ : same picture with aperio soft ware notice laminin positive reactivity in foci $3^{\text {rd }}$ week, laminin $\mathrm{Ab}$, $\mathrm{X} 20$ )

\section{Quantitative morphometric assessment of laminin expression in regeneration}

Statistical analysis (SAS) was used to assess the difference in the expression of Laminin reactivity, which was assessed using Aperio Alogrthem software. The degree of positivity measured by this program ranged and expressed in different colors. Laminin reactivity in muscles in the control group shoed $0.293 \pm 0.02$ (pixel/micron) ${ }^{2}$ and a value of $0.321 \pm$ 

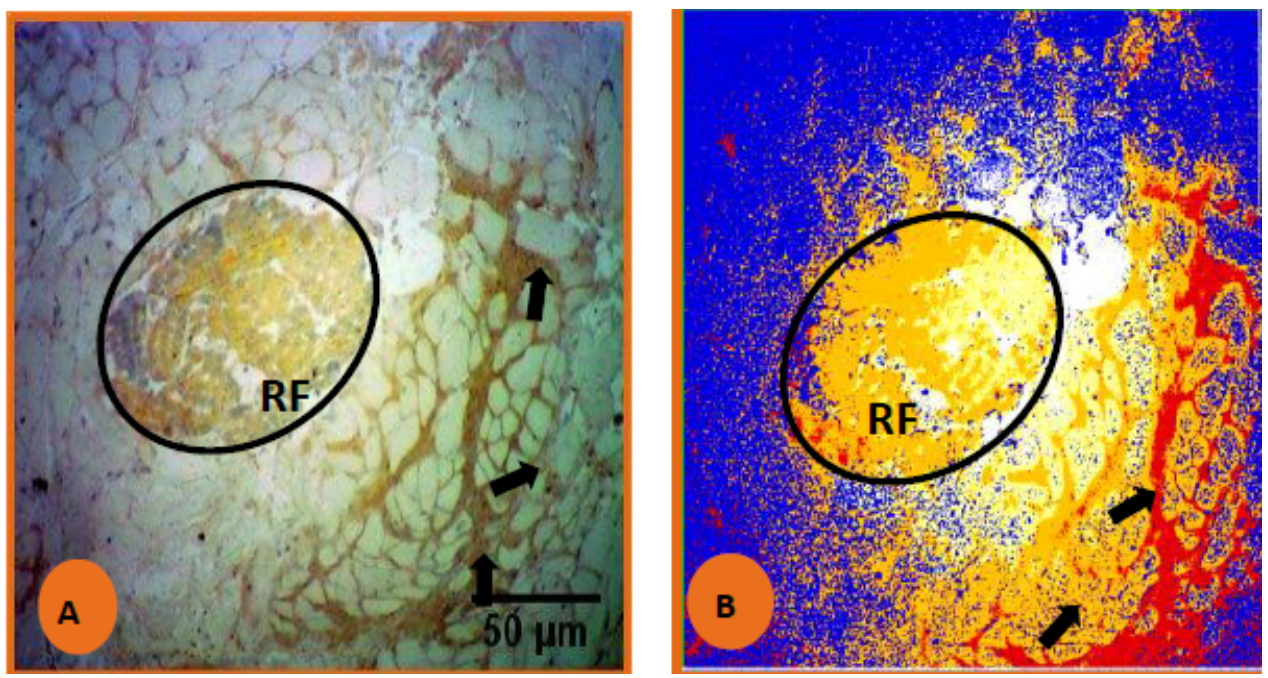

Figure 8 A: difference of laminin reactivity between regenerating area \&peripheral intact muscle the regenerative foci (RF) new cell showed marked sarcoplasmic reactivity B: The same picture seen with Aperio software showing position foci \& blue regenerative area represent mature peripheral muscle fiber (laminin Ab, $6^{\text {th }}$ week, X20).
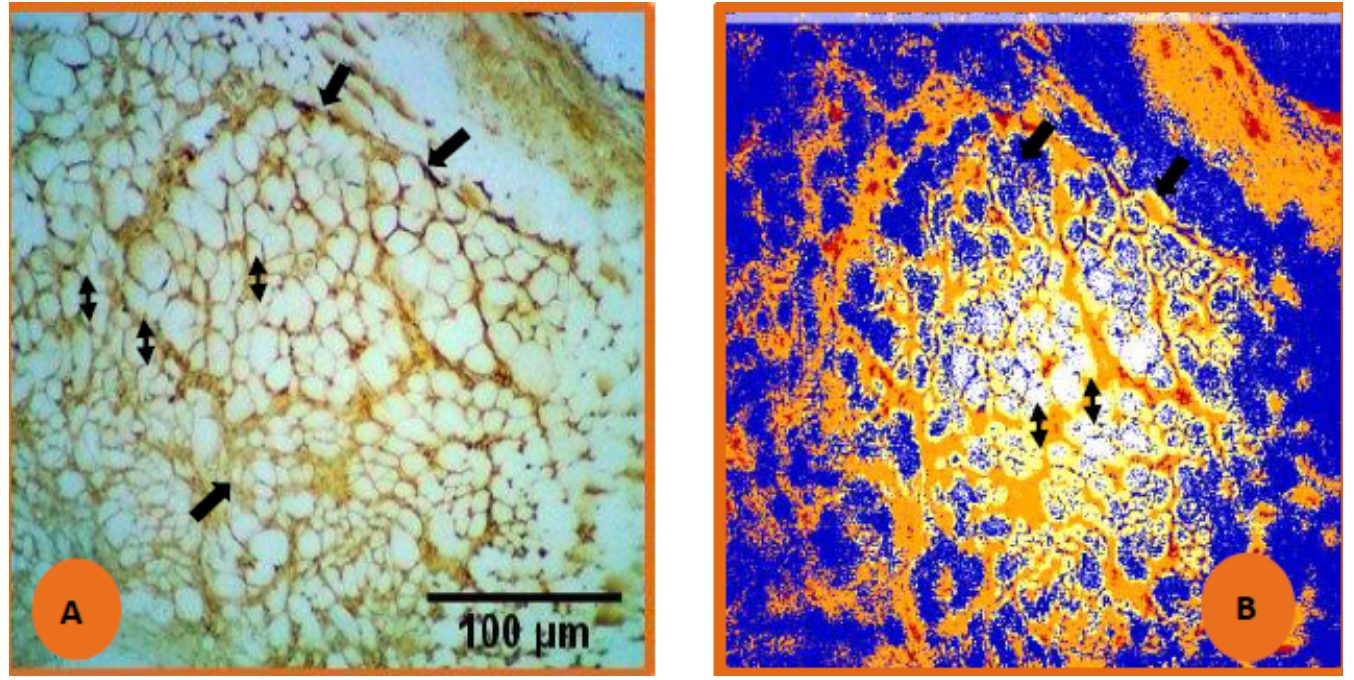

Figure 9 Section of skeletal muscle regeneration showing A: complete muscle regeneration with laminin Ab expression confined only to endomysium (two head arrow) and perimysium (one head arrow) with the negative sarcoplasmic activity of laminin. B: The same picture in aperio software (laminin Ab, $6^{\text {th }}$ week, X10). 
0.02 (pixel/micron) $)^{2}$ in the $6^{t h}$-week groups, while in the $3^{r d}$ postoperative week group the positive expression of Laminin recorded of $0.724 \pm 0.03$ (pixel/micron) ${ }^{2}$.

These differences were statistically significant $(\mathrm{P}$-value $=0.0373)$ no statistically significant difference was found between control and $6^{\text {th }}$ postoperative weeks $\mathrm{P}$-value $\leq 0.05$ according to independent t-test application (Table 1).

Table 1 Laminin expression in different experimental groups

$\begin{array}{llc}\text { Groups } & \text { Mean } \pm \text { SEM (Pixel/Micron) } & \text { P-value } \\ \begin{array}{l}\text { Laminin expression in control } \\ \text { group }\end{array} & 0.293 \pm 0.02 \mathrm{~B} & 0.0001 \\ \begin{array}{l}\text { Laminin expression in } 3^{\text {rd }} \text {-week } \\ \text { group }\end{array} & 0.724 \pm 0.03 \mathrm{~A} & \\ \begin{array}{l}\text { Laminin expression in } 6^{\text {th }} \text { week } \\ \text { group }\end{array} & 0.321 \pm 0.02 \mathrm{~B} \\ * *(\mathrm{P}<0.01) . \text { Means having with the different letters in the same column differed significantly. }\end{array}$

\section{DISCUSSION}

The time schedule of the main events during muscle regeneration is essential and forms an overlapping schedule and superimposed process; these stages included in the regeneration of injured muscles are revascularization reinnervation, and lastly, the establishment of tendon connection the mention above process are crucial stages for muscle regeneration. ${ }^{7}$

In this study, the stages mentioned above were well identified clearly during postoperative follow- up in different groups. Overlapping stages of both degenerations, where muscle start to fragment and come what is called ghost cells and regeneration, was well documented. On the other hand, revascularization was seen at the same time as the degenerative stage. Revascularization is the crucial regenerative event that happens early after trauma; the pattern of revascularization in regenerating muscle is related to the number of mononuclear inflammatory cells that invade the traumatic area in the early stages of degeneration. ${ }^{8}$

Newly formed muscle fibers were seen at the beginning of the regenerative process at the $3^{\text {rd }}$ postoperative week cell; these were small rounded muscles with centrally located nucleus usually mononucleotide and myofilaments were not settled yet they are named some time as type $2 \mathrm{C}$ fibers.

These fibers are considered one of the most important key stages of regeneration. They are the start point of the formation of new muscle fibers; eventually, they gain maturity with the advancement of time and form mature skeletal fibers. ${ }^{9}$

Muscle regeneration is a dynamic process due to the activation of multiple factors, including satellite cell, fibronectin, laminin, and fibroblast growth factors in the initial proliferative phase called the regeneration. Components of muscle regeneration, both structurally and functionally, are under the effects of these factors plus other environmental fac- 
tors. ${ }^{10}$

The regenerative process was thoroughly investigated after experimental trauma to extensor digitorum longus muscle and showed a different profile of reactivity in different post-traumatic times. Early myogenic cell differentiation and formation of new muscle fibers and early myotube formation showed an intense reactivity for Laminin.

Laminin 211 and 111 are highly expressed through regenerative processes induced by a crush injury expressed in the basement membrane of small diameter myofibers, which exist and represent the newly regenerated muscle fibers suggesting their involvement in early myogenic differentiation and are intensively present during the process of new muscle fibers changing to myotube newly formed showed a highly express Laminin and alpha 6 integrin. ${ }^{11}$

The significance of Laminins for muscle integrity through complex expression patterns in making basement membrane is manifested in congenital muscular dystrophies with basement membrane through muscle development and constitute a growing family of proteins muscle, also through characterization and communication events through muscle formation. Laminin enhances muscle regeneration and improves myoblast proliferation, and can facilitate the regeneration process in the studies involved in muscle development. ${ }^{12}$

Laminin plays an important role in cell migration after trauma and this, in turn, enhance healing and even enhance early wound closure of the postoperative wound by enhancing the migration of mononuclear cells and enhancement of division of myoblast and myotube together with activation of surrounding fibroblast and lastly stimulation of endothelial cells surrounding blood vessels all together played an important role that yielded good regenerative capacity of skeletal muscle to regenerate. ${ }^{13}$

Revascularization and formation of different types of blood vessels were well-established criteria in this study by $\mathrm{H} \& \mathrm{E}$ and by using Laminin, Abs. In a study done by Malinda et al., 2008, they recorded the presence of high, multiple types of vascularity in the first $3^{\text {rd }}$ post-traumatic period. Laminin was expressed in the basement membrane of all blood vessels present surrounding the injury area. This same study indicated that wound healing was well established; they investigate and found that migration of myoblast and matrix metalloproteinase was involved in the formation of new blood vessels, and Laminin seem to have a direct effect or remolding of collagen fibers. ${ }^{14}$

The statistical data of the quantitative study of the Laminin during the process of degeneration and regeneration showed rather a different manner of expression of this marker between the two studied groups. Control and $6^{\text {th }}$ postoperative groups showed less intense reactivity towards Laminin $(211 \& 111)$, while a heavy intense reactivity was detected and was a significant difference in the $3^{r d}$-week group. Statistical analysis showed $0.293 \pm$ 0.02 pixel $/(\text { micron })^{2}$, control $3^{r d}$ post-operative week $0.724 \pm 0.03$ pixel $/(\text { micron })^{2}$ and $6^{\text {th }}$ post-operative weeks $0.321 \pm 0.02$ pixel $/(\text { micron })^{2}$.

The sticking feature of the presence of Laminin in the sarcoplasm of newly formed muscle and surrounding connective tissue elements, including their blood vessels, was behind the significant-high reactivity seen in the $3^{r d}$-week group. Laminin sarcoplasmic distribution during process of myogenesis after muscle trauma still unexplained criteria, the 
endomysium absence in the stage was recorded in a study which demonstrates the fact that can explain the Laminin expression inside the sarcoplasm, the high bundling of Laminin at the period of myogenesis may be due to it to the bundling of sarcoplasmic elements as theses cell at this period lack endomysial present. ${ }^{15}$

The importance of Laminin to the integrity of skeletal muscle has been demonstrated through extensive analyses of both naturally occurring and targeted mutations in Laminin genes. All adult skeletal muscle fibers are surrounded by an abasement membrane containing primarily Laminin; although Laminin also appears to be present, the absence of or alteration in the Laminin alpha 2 chain is thought to weaken the skeletal muscle contractions. The muscle sarcoma basement membrane is unusual in that it processes a topographical pattern of alternating densities that corresponds to an underlying receptor and cytoskeletal array mediator of force transmission between muscle fibers. ${ }^{16}$

During human skeletal muscle development, distribution and expression characteristics of laminin alpha 2 in primary human skeletal muscle cells were assessed; expression levels of all three protein increased with differentiation; the protein was relocated from sarcoplasm to the sarcolemma both alpha and beta- dystroglycan was involved in forming a complex with their respective partners. Laminin alpha2 during development cells may employ tightly regulated post-translational species -species modification to produce different isoforms of alpha-dystroglycan to participate in appropriate.

From this study, it was concluded that the process of regeneration is a dynamic type where degeneration and regeneration superimposed each other. This study's outcome was integrated by using Laminin, which gives a rational perspective on the role of Laminin in the process of regeneration.

\section{ACKNOWLEDGMENTS}

None.

\section{DECLARATIONS}

\section{Authors' contributions}

All authors have equally contributed to this work. They reviewed and approved the final version of this article before publication.

\section{Conflict of interest}

There are no conflicts of interest to declare.

\section{Ethical approvals}

This study was reviewed and approved by the Institutional Review Board at the College of Medicine, University of Al-Nahrain. 


\section{Data availability}

The data that support the findings of this study are available from the corresponding author, upon reasonable request.

\section{Funding resources}

This work didn't receive any fund.

\section{REFERENCES}

1. Musarò A. The Basis of Muscle Regeneration. Advances in Biology. 2014;2014:1-16. Available from: 10.1155/2014/612471; https://dx.doi.org/10.1155/2014/612471.

2. Menetrey J, Kasemkijwattana C, Day CS, Bosch P, Vogt M, Fu FH, et al. Growth factors improve muscle healing in vivo . Journal of Bone and Joint Surgery British volume . 2000;82(B(1)):131-137. Available from: 10.1302/0301-620x.82b1.0820131.

3. MOURKIOTI F, ROSENTHAL N. IGF-1, inflammation and stem cells: interactions during muscle regeneration. Trends in Immunology. 2005;26(10):535-542. Available from: 10.1016/j.it.2005.08.002;https://dx.doi.org/10.1016/j.it.2005.08.002.

4. Yurchenco PD. Basement Membranes: Cell Scaffoldings and Signaling Platforms. Cold Spring Harbor Perspectives in Biology. 2011;3(2):a004911-a004911. Available from: 10.1101/cshperspect.a004911;https://dx.doi.org/10.1101/cshperspect. a004911.

5. Talts JF, Sasaki T, Miosge N, Göhring W, Mann K, Mayne R, et al. Structural and Functional Analysis of the Recombinant G Domain of the Laminin $\alpha 4$ Chain and Its Proteolytic Processing in Tissues. Journal of Biological Chemistry. 2000;275(45):35192-35199. Available from: 10.1074/jbc.m003261200;https://dx. doi.org/10.1074/jbc.m003261200.

6. Calinski T, Steel RGD, Torrie JH. Principles and Procedures of Statistics: A Biometrical Approach. 1981;37(4):859.

7. Schiaffino S, Dyar KA, Ciciliot S, Blaauw B, Sandri M. Mechanisms regulating skeletal muscle growth and atrophy. FEBS Journal. 2013;280(17):4294-4314. Available from: 10.1111/febs.12253;https://dx.doi.org/10.1111/febs.12253.

8. Ciciliot S, Schiaffino S. Regeneration of Mammalian Skeletal Muscle: Basic Mechanisms and Clinical Implications. Current Pharmaceutical Design. 2010;16(8):906914. Available from: 10.2174/138161210790883453;https://dx.doi.org/10.2174/ 138161210790883453.

9. Negroni E, Butler-Browne GS, Mouly V. Myogenic stem cells: regeneration and cell therapy in human skeletal muscle. Pathologie Biologie. 2006;54(2):100108. Available from: 10.1016/j.patbio.2005.09.001; https://dx.doi.org/10.1016/j. patbio.2005.09.001.

10. Riederer I, Bonomo AC, Mouly V, Savino W. Laminin therapy for the promotion of muscle regeneration. FEBS Letters. 2015;589(22):3449-3453. Available from: 10. 1016/j.febslet.2015.10.004; https://dx.doi.org/10.1016/j.febslet.2015.10.004. 
11. Marcinczyk M, Elmashhady H, Talovic M, Dunn A, Bugis F, Garg K. Laminin111 enriched fibrin hydrogels for skeletal muscle regeneration. Biomaterials. 2017;141:233-242. Available from: 10.1016/j.biomaterials.2017.07.003; https://dx. doi.org/10.1016/j.biomaterials.2017.07.003.

12. Holmberg J, Durbeej M. Laminin-211 in skeletal muscle function. Cell Adhesion \& Migration. 2013;7(1):111-121. Available from: 10.4161/cam.22618;https://dx.doi. org/10.4161/cam.22618.

13. Malinda KM, Wysocki AB, Koblinski JE, Kleinman HK, Ponce ML. Angiogenic laminin-derived peptides stimulate wound healing. The International Journal of Biochemistry \& Cell Biology. 2008;40(12):2771-2780. Available from: 10.1016/j.biocel. 2008.05.025; https://dx.doi.org/10.1016/j.biocel.2008.05.025.

14. Buckingham M, Rigby PWJ. Gene Regulatory Networks and Transcriptional Mechanisms that control Myogenesis . In: and others, editor. Developmental cell ; 2014. Available from: https://doi.org/10.1016/j.devcel.2013.12.020.

15. Yurchenco PD. Loss of basement membrane, receptor and cytoskeletal lattices in a laminin-deficient muscular dystrophy. Journal of Cell Science. 2004;117(5):735-742. Available from: 10.1242/jcs.00911; https://dx.doi.org/10.1242/jcs.00911.

16. CHEN L, BURGUNDER J. In vitro developmental expression of dystroglycan and laminin- $\alpha 2$ in human skeletal muscle. Cell Biology International. 2005;29(7):506513. Available from: 10.1016/j.cellbi.2005.01.009; https://dx.doi.org/10.1016/j.cellbi. 2005.01.009. 